Original Research Article

\title{
Drug promotional literature: Does pharmaceutical industry follow WHO guidelines?
}

\author{
Priyanka G. Sonwane*, Ashwini V. Karve
}

Department of Pharmacology, Topiwala National Medical College, Mumbai 400008, Maharashtra, India

Received: 09 May 2017 Accepted: 06 June 2017

\section{*Correspondence to:}

Dr. Priyanka G. Sonwane, Email:pgs.s1988@gmail.com

Copyright: (C) the author(s), publisher and licensee Medip Academy. This is an openaccess article distributed under the terms of the Creative Commons Attribution NonCommercial License, which permits unrestricted noncommercial use, distribution, and reproduction in any medium, provided the original work is properly cited.

\begin{abstract}
Background: Promotional literature is an important tool for both pharmaceutical industry (marketing strategy) and physicians (up to date knowledge). Important ways of doing drug promotion are visual aids, leave behind, flip charts. World Health Organisation has laid down criteria for drug promotional literature.

Methods: A cross sectional observational study was performed in Department of Pharmacology, Tertiary Care Teaching Hospital of Mumbai. Total 137 drug promotional Literatures were randomly collected from different outpatient departments out of which 37 were excluded. 100 drug promotional literatures were evaluated by using WHO guidelines.

Results: None of drug promotional literature fulfilled all WHO criteria. Though name of the active ingredient and brand name featured in $100 \%$ of the literature, $69 \%$ of them lacked information related to adverse drug reactions, precautions, contraindications and warnings. The approved therapeutic uses were mentioned in $96 \%$ but the dosage regimen in $38 \%$ only. Majority of the literature $(80 \%)$ did not mention the drug interactions. References were given in $76 \%$ of the literature of which $87 \%$ were from journal article.

Conclusions: Pharmaceutical industries do not follow WHO guidelines in toto to promote their product. Thus more strict regulations need to be implemented for proper promotion and dissemination of information about new drugs.
\end{abstract}

Keywords: Marketing strategy, Pharmaceutical industries, Promotional literature, References, WHO guidelines

\section{INTRODUCTION}

Large numbers of new drugs are introduced into the market every day. Pharmaceutical companies are in the business of development and sell of new drugs. These are accepted in health care system through physicians, and its availability is of little value unless the physician is aware of its existence and has scientific information to use it effectively. ${ }^{1,2}$ Pharmaceutical companies use different modes of drug promotion which include visual aids, leave behinds, leaflets and audio visuals. In private or public clinic set-up direct to physician (DTP) marketing is major method used by drug manufacture companies and distributors. ${ }^{3}$ Many a times, it is the only source on which treating physicians depend on for updating their knowledge about the existing and novel drugs. ${ }^{4}$ Many of physicians currently get their information from commercial sources, usually through well set network of medical representatives. ${ }^{5}$

Pharmaceutical companies spend large amount of money on drug promotions. In 2005, a pharmaceutical industry in the USA has spent more than 30 billion dollars in marketing and promoting to enlighten the clinicians about their products. ${ }^{6}$ Such marketing influences clinician's prescribing behaviour with or without benefitting the patient. 
According to World Health Organization (WHO), medicinal drug promotion refers to "all informational and persuasive activities by manufacturers and distributors, the effect of which is to induce the prescription, supply, purchase, and/or use of medicinal drugs". ${ }^{7}$ Hence, for the rational use of drugs, WHO has laid down ethical criteria for medicinal drug promotion and has recommended pharmaceutical industries to implement these guidelines. ${ }^{8}$ There are universally applicable baseline standards coded by International Federation of Pharmaceutical Manufacturers and Associations (IFPMA) for marketing practice, and these standards apply to all promotional communications from the pharmaceutical industry to the medical profession.

In India, promotional activities by pharmaceutical companies are governed by Organization of Pharmaceutical Producers of India (OPPI), selfregulatory code of pharmaceutical marketing practices, January and by National legislation. ${ }^{9}$

WHO has published ethical criteria for medicinal drug promotion to support and improve health care by promoting rational use of medicines. Therefore, it is essential to critically and scientifically evaluate the drug promotional literature as such promotional activities influence the prescribing behaviour of the physicians. Since last many years ethical promotion and authenticity of such drug promotion considered as the subject of debate. ${ }^{10}$ Few studies have observed that information provided in drug promotional literatures are varying with the code of ethics..$^{8,11,12}$ So, this may affect the drug prescription, utilization, and sometimes can be irrational. Hence, this study was conducted to evaluate the completeness of the promotional drug literature using the WHO guidelines.

\section{METHODS}

This was a cross sectional observational and single centered study carried out in the Department of Pharmacology of Tertiary Care Teaching Hospital of Mumbai for period of 2 months from January 2017 to February 2017.

The study was conducted to find out the scientific and ethical status of drug promotional literatures presented to prescribers and its concurrence to 'WHO criteria for ethical medicinal drug promotion, 1988.' Total 137 drug promotional literatures were randomly collected from different outpatient departments. Literatures promoting medicinal devices and equipments (Insulin pump, blood glucometer, etc.), orthopaedic prosthesis and ayurvedic medicines, drug monographs, reminder advertisements, drug lists, and literature promoting more than two brands were excluded from the analysis.

The following are the WHO criteria to be followed by pharmaceutical industries for the completeness of drug promotional literature: ${ }^{7}$
- $\quad$ The name(s) of the active ingredient(s) using either international non-proprietary names (INN) or the approved generic names of the drug

- The brand name

- Content of active ingredient per dosage form or regimen

- Name of other ingredients known to cause problems, i.e., adjuvant

- $\quad$ Approved therapeutic uses

- Dosage form or regimen

- $\quad$ Side effects and major adverse drug reaction

- $\quad$ Precautions, contraindications, and warnings

- Major interactions

- Name and address of the manufacturer or distributor

- $\quad$ Reference to scientific literature as appropriate.

All the literatures were evaluated for completeness of the information for each parameter mentioned above. The drug promotional literatures were also analysed for source and year of references used to defend the drug promotional literature claims. Descriptive statistics were used to analyse the data. The data were expressed as percentage.

\section{RESULTS}

Out of total 137 drugs promotional literatures screened, 37 were excluded as per exclusion criteria and 100 were evaluated for its concurrence with WHO guidelines. None of drug promotional literature fulfilled all WHO criteria. Though name of the active ingredient and brand name featured in $100 \%$ of the literature, content of active ingredient per dosage form was mentioned in 100\%, name and address of pharmaceutical company were mentioned in $64 \%$ of literatures while abbreviated prescribing information was depicted only in $38 \%$, references were mentioned in $76 \%$ of drug promotional literatures as shown in Figure 1.

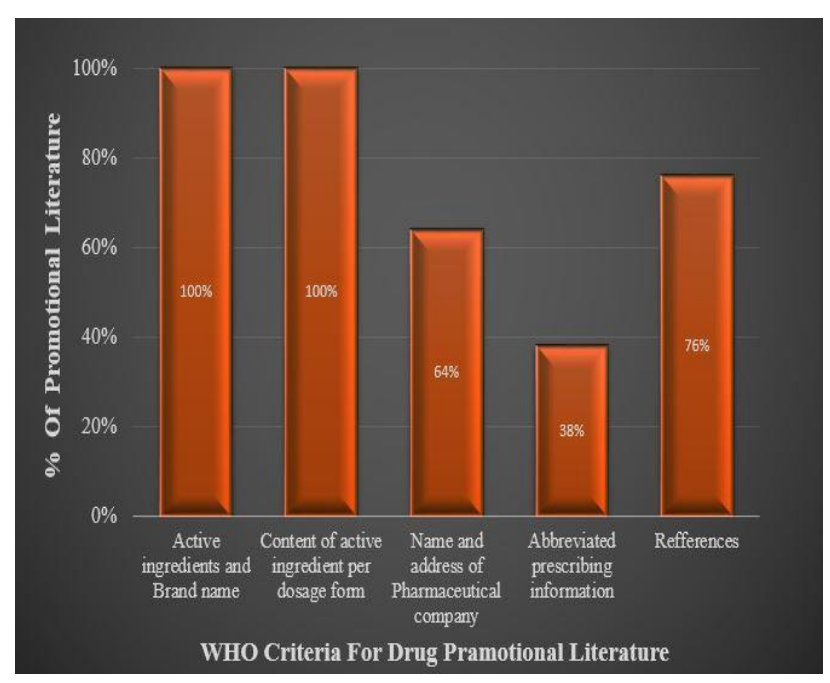

Figure 1: Analysis of promotional literature among the WHO criteria. 
In abbreviated prescribing information; therapeutic uses were found in $96 \%$ of drug promotional literature, side effect, major drug interaction, precaution, contraindication and warning was mentioned in only $31 \%$ of drug promotional literature. While major interaction and name of other ingredient known to cause problem were given in $20 \%$ only as depicted in Figure 2.

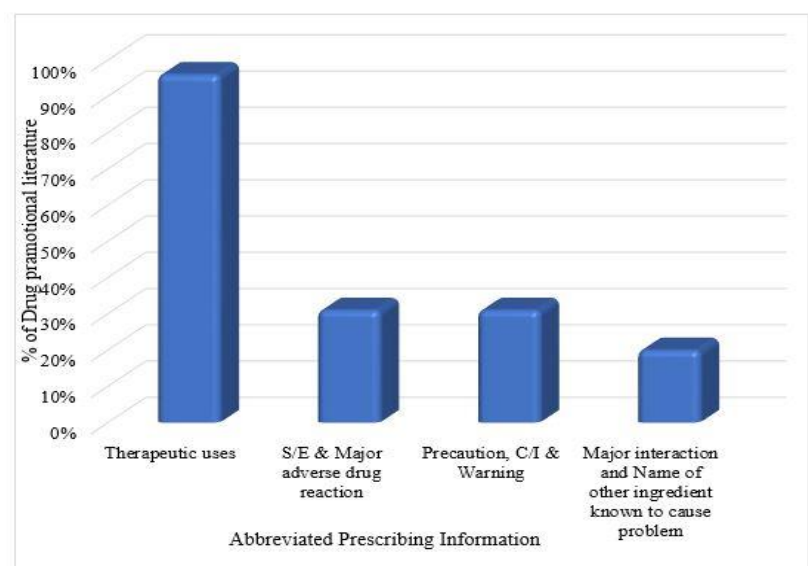

Figure 2: Abbreviated prescribing information as per WHO criteria.

References were given only in $76 \%$ of literatures. Total number of references was 176 , out of which $153(87 \%)$ were from journal article, $4 \%$ from websites, $2 \%$ from textbooks and $7 \%$ from other sources. Among the journal article references $58(38 \%)$ were after 2010 and $95(62 \%)$ were before 2010 (Table 1).

\section{Table 1: Sources of various references in drug promotional literature.}

\begin{tabular}{|l|l|l|}
\hline $\begin{array}{l}\text { References } \\
\begin{array}{l}\text { Total no. of references } \\
\text { cited }\end{array}\end{array}$ & 176 & $100 \%$ \\
\hline $\begin{array}{l}\text { Journal article } \\
\text { reference, Categorised } \\
\text { by publication date }\end{array}$ & 153 & $87 \%$ \\
\hline After 2010 & 58 & $38 \%$ \\
\hline Before 2010 & 95 & $62 \%$ \\
\hline Website & 7 & $4 \%$ \\
\hline Textbook & 3 & $2 \%$ \\
\hline Other Sources & 13 & $7 \%$ \\
\hline
\end{tabular}

\section{DISCUSSION}

Every year, lots of new drugs enter the Indian market. Many of them are "me too" products, not genuine innovations. They join more than 20,000 drug formulations already in the market., ${ }^{5,8}$ Marketing new drugs to physicians is an important strategy adopted by pharmaceutical companies. Direct to physician (DTP) marketing is one very important facet of the promotion of pharmaceutical companies. ${ }^{10}$ Promotional literatures are sometimes the only source to the physician about new drugs or new indications for old drugs. Most physician are dependent on commercial sources of drug information from medical representatives, drug advertisement brochures etc., and it has great impact on their prescribing behaviour. ${ }^{8}$ Thus promotional literature should be accurate and contain all the information needed by the prescribing physician. It would minimise irrational prescriptions, incidence of drug resistance, adverse effects, and to reduce the cost incurred by patients. ${ }^{10}$

In our study, it was observed that none of the drug promotional literatures fulfilled all the criteria laid down by the WHO guidelines. A similar finding was reported in other studies..$^{2,8,11,13}$ On the basis of the observations of this study, it was seen that majority of the literatures had mentioned INN of each active ingredient $(100 \%)$ but the recommended dosage form was mentioned in only $38 \%$. Out of all the literatures, $60-70 \%$ were lacking in information related to duration of therapy, and dose adjustments in special situations like pregnancy, lactation, liver or kidney diseases etc., Most neglected aspect of drug promotion was information about adverse drug reactions, drug interactions, precautions, and over dosage $(>70 \%)$. Similar findings were observed in study carried out by khakhkhar et all. ${ }^{8}$ Only $20 \%$ of the promotional literature had mentioned other ingredients that are known to cause problems.

References were mentioned in $76 \%$ of drug promotional literature. Most of the references noted were from journal article out of which $38 \%$ of references were after 2010 and $62 \%$ were before 2010 . Most of drug promotional literature were published recently i.e. within 1 year, but large number of journal article references were before 2010. It is highly unlikely that no new data about the concerned drug has been published in the recent years. Thus pharmaceutical industry should provide physicians the most recent evidence published about their drugs. This would help the physicians to prescribe the drugs rationally.

The association of pharmaceutical companies in developed countries, e.g. UK, Australia, and Canada are required to observe a code of practice in marketing as a signatory condition. ${ }^{14}$ In India, there are regional Ethics Committees for complaints against unethical drug promotion advertisements. Drug controller authority takes necessary legal steps in response to such complaints to against drug manufacturers and distributors., ${ }^{2,5,8}$ DTP method of marketing definitely influences prescribing behaviour of the physicians. Development of necessary laws and their implementation by drug manufacturers, practitioner's awareness and strengthening of existing guidelines can be useful measures in this matter. It requires group efforts of physicians, pharmaceutical companies and regulatory body which can ultimately led to ethical drug promotional activities and rational prescribing. 
One of limitations of the study was small sample size. Also study was conducted in government hospital and it was single centred study. In this study only one type of promotional literature was analysed, i.e. printed promotional literature; however, there is need to assess the awareness of the physicians by interventional study and provide guidance about accurate and ethical information from drug promotional literatures.

\section{CONCLUSION}

None of the drug promotional literatures fulfilled $100 \%$ criterion led by WHO for medicinal drug promotion. Most of them were lacking in scientific and critical information. Therefore, pharmaceutical industry should make a conscious attempt to follow the WHO guidelines in toto. Also the concerned authority should make it mandatory for the industry to follow the said guidelines. And thus provide the physicians with complete information about the drug.

\section{Funding: No funding sources}

Conflict of interest: None declared

Ethical approval: Not required

\section{REFERENCES}

1. Stimson GV. Information contained in drug advertisements. BMJ. 1975;4:508-9.

2. Mali SN, Sujata D, Bachewar NP. Evaluation of rationality of promotional drug literature using world health organization guidelines. Ind $\mathbf{J}$ Pharmacol. 2010;42(5):267-72.

3. Medhi B, Prakash A. Ideal characteristics of promotional literature. In Practical Manual of Experimental and Clinical Pharmacology. $1^{\text {st }}$ Edition. India: JBPMP; 2010:342-345.

4. Phoolgen S, Kumar SA, Kumar RJ. Evaluation of the rationality of psychotropic drug promotional literatures in Nepal. J Drug Discov Ther. 2012;2:6-8.

5. Gopalakrishnan S, Murali R. India: Campaign to tackle unethical promotion. Essential drugs monitor. [Online],

2002.

Available http://www.apps.who.int/medicinedocs/pdf/s4937e/s4 937e.pdf. [Accessed 3rd April 2017]

6. Kornfield R, Donohue J, Berndt ER, Alexander GC. Promotion of prescription drugs to consumers and providers, 2001-2010. PLoS One 2013;8:e55504

7. Ethical criteria for medicinal drug promotion. World Health Organization [Online]. 1988 May 13; [8 screens] Available at: http://www.who.int/medicinedocs/collect/edmweb/pd f/whozip08e/whozip08e.pdf. [Last accessed on 2017 April 3].

8. Khakhkhar T, Mehta M, Sharma D. Evaluation of drug promotional literatures using WHO guidelines. J Pharm Negative Results. 2013;4:33-8.

9. OPPI code of pharmaceutical marketing practices. Available at: URL: http://www.indiaoppi.com/OPPI\%20Code\%20of\%20 Marketing\%202007.pdf [Online]. 2017 April. [Last accessed on 2017 April 3].

10. Villanueva P, Peiro S, Librero J, Pereiro I. Accuracy of pharmaceutical advertisements in medical journals. The Lancet. 2003;361(9351):27-32.

11. Jadav SS, Dumatar CB, Dikshit RK. Drug promotional literatures (DPLs) evaluation as per World Health Organisation (WHO) criteria. J App Pharm Sci. 2014;4:84-8.

12. Alam K, Shah AK, Ojha P, Palaian S, Shankar PR. Evaluation of drug promotional materials in a hospital setting in Nepal. South Med Rev. 2009;2:2-6.

13. Ganashree P, Bhuvana K, Sarala N. Critical review of drug promotional literature using the World Health Organization guidelines. Journal of Research in Pharmacy Practice. 2016 Jul;5(3):162.

14. Lexchin J. Enforcement of codes governing pharmaceutical promotion: What happens when companies breach advertising guidelines? CMAJ. 1997;156:351-6.

Cite this article as: Sonwane PG, Karve AV. Drug promotional literature: Does pharmaceutical industry follow WHO guidelines? Int J Basic Clin Pharmacol 2017;6:1790-3. 